\title{
Importancia del grabado como herramienta de desarrollo de ambos hemisferios del cerebro
}

\begin{abstract}
Resumen. Este artículo trata sobre la importancia del Grabado para el desarrollo de ambos hemisferios del cerebro, de acuerdo a los estudios en el campo cognitivo así como en la neurociencia han dado aportes importantes sobre los procesos del cerebro para la construcción de conocimientos, las capacidades de cada hemisferio y las potencialidades que se alcanzan cuando actúan Es por esta razón que el Grabado por las características de sus procesos técnicos y estéticos contribuyen en forma significativa a poner en práctica ambos hemisferios del cerebro desarrollando no solo nuevas capacidades a nivel cognitivo y creativo sino a potenciar al futuro profesional logrando pensamientos más complejos en el campo de las artes plásticas y del diseño gráfico.
\end{abstract}

\section{Palabras clave:}

Grabado

Cognición

Neurociencia y plasticidad cerebral

Hemisferios del cerebro

Construcción del aprendizaje

Introducción. "Si el siglo XIX fue el siglo de industrialización y el siglo XX, el siglo de los avances científicos y de la sociedad del conocimiento, el siglo XXI está llamado a ser el siglo de la creatividad, por la exigencia de encontrar ideas y soluciones nuevas a los muchos

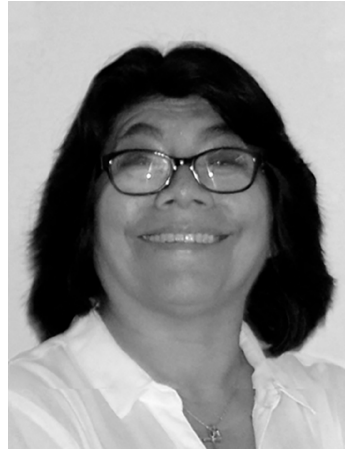

Mtra. Liliana Melchor Aguero Escuela Nacional de Bellas Artes

Universidad Cesár Vallejo lilianamelchor22@gmail.com Lima, Perú. 
problemas que se plantean en una sociedad de cambios acelerados, adversidades y violencia social" (Saturnino de la Torre, 2006, pág. 12).

La industrialización, los avances a nivel científico e industrial ha repercutido en daños al medio ambiente, reflejado en el campo climático y ecológico, como el calentamiento global, lo cual nos da lamentablemente un panorama desolador, irreversible, asimismo se acrecientan problemas de pobreza y deterioro de valores.

Ante este panorama se genera la necesidad de cambios fundamentales en el pensar, actuar y ser de las personas, la educación debe orientarse en la búsqueda de nuevas herramientas y modelos pedagógicos que desarrollen en los estudiantes capacidades que respondan a estas necesidades, generar otros tipos de competencias acordes al actual panorama.

En el campo de las Artes y el Diseño Gráfico las investigaciones en el campo educativo dan importancia al desarrollo de la capacidad creativa necesaria en la formación humana del estudiante, pero hoy en día se considera la importancia de desarrollar también la capacidad analítica, racional.

En el desarrollo de la propuesta creativa se plantean conflictos cognitivos, hoy en día con los avances en investigaciones sobre cognición, neurociencia y procesos creativos existe información sobre estos aspectos en los cuales están involucrados procesos más complejos de pensamiento. Aquí radica la importancia de la técnica del Grabado que por sus características estéticas y técnicas contribuye a los proceso cognitivos racionales y creativos.

Conceptos. Al comenzar a ver el tema de como aprendemos y como adquirimos conocimiento y que capacidades debemos desarrollar para ello debemos mencionar lo relacionado a estudios sobre estos temas y como han contribuido evolucionado.

Cognitivismo. Es una corriente que surge alrededor de los 50 como una reacción a la corriente conductista, se especializa en estudiar los procesos mentales relacionados con el conocimiento la cual considera el aprendizaje como un proceso activo y dinámico en donde el estudiante tiene que participar de su propio aprendizaje. Asimismo, considera al arte como una disciplina en donde los procesos creativos son mentales reconociendo que desde la disciplina artística se pueden desarrollar habili- dades y destrezas para la construcción del conocimiento. Jean Piaget, psicólogo, basó sus estudios en la cognición humana y en la práctica educativa, consideraba que esta no debía basarse en la copia y la memorización, planteó que el conocimiento se adquiere a partir del proceso constructivo que va a realizar el sujeto con su entorno social; así el aprendizaje tiene que ser entendido como un proceso de adaptación de las estructuras mentales del sujeto con su entorno. (Trilla, 2002).

Howard Garner (1994), miembro del Proyecto Cero en Harvard, también basa sus estudios en la cognición. Él plantea que la neurología y la nueva ciencia cognitiva consideran la necesidad de superar el esquema clásico de la inteligencia y sustituirlo por una concepción multiforme de esta, que los modelos que hablan sobre inteligencia como una sola no están considerando la gran complejidad de la mente humana. Uno de sus estudios se centra en la mente humana de niños y adultos, en esta investigación llega al concepto de inteligencias múltiples, las cuales se relacionan con las capacidades humanas.

De acuerdo a Efland (2004), profesor de educación artística "Con esta postura, estuvo en desacuerdo con la creencia de Piaget de que el pensamiento lógico-científico estaba por encima de otras manifestaciones de la inteligencia". Gardner postula que las capacidades cognitivas de los seres humanos son siete:la inteligencia lingüística, la lógico matemática, la física-cinestésica, la musical, la especial y la social, que se divide en dos, la interpersonal y la intrapersonal. Mas adelante añadió una octava, a la que llamo inteligencia naturalista planteando con esto que las personas tienen distintos potenciales y estilos cognitivos. Gardner propone que la escuela se centre en la persona para que pueda desarrollar estas inteligencias y no únicamente en dos, la inteligencia lingüística y la lógico matemática, que son las que normalmente se desarrollan en las escuelas tradicionales.

La neurociencia y la plasticidad cerebral. Begley (2008), afirma que "el cerebro es el órgano del comportamiento y el depósito del aprendizaje y la memoria, el cerebro cambia de una manera real y fisica cuando adquirimos conocimientos nuevos, dominamos una nueva destreza y nos olvidamos de las cosas que han ocurrido". Es decir, en el proceso de enseñanza - aprendizaje, el docente universitario puede lograr que sus estudiantes modifiquen sus estructuras mentales, a nivel cognitivo, instrumental y afectivo, provocando así cambios físicos estructurales en su cerebro, en las diversas redes y circuitos neuronales que conforman sus áreas, zonas y sitios, de ahí 
que "cuando las neuronas se activan simultáneamente, sus conexiones sinápticas se hacen más fuertes, aumentando la posibilidad de que la activación de una, estimule la activación de la otra".

Según Gómez (2004) mencionado por López, el“cerebro tiene una capacidad muy potente y bien desarrollada para cambiar en respuesta a las demandas del ambiente. Éste comprende la creación y el fortalecimiento de algunas conexiones neuronales y el debilitamiento o la eliminación de otras".

Martínez-Morga, Martínez,S (2016), los autores citados afirman que "La plasticidad neuronal se puede definir como la capacidad de una neurona o red neuronal para modificarse funcional o estructuralmente en respuesta a los cambios de su actividad".

Aquí radica la importancia y responsabilidad de la educación a nivel superior para propiciar experiencias educativas que contribuyan a desarrollar nuevas conexiones entre ambos hemisferios del cerebro y desarrollar capacidades inherentes a su profesión.

Hemisferios del cerebro. Los primeros estudios realizados sobre las funciones de los hemisferios del cerebro dieron mayor importancia al hemisferio cerebral izquierdo por su capacidad de aprender, memorizar y educar, dejando relegado al hemisferio cerebral derecho. Se pensó que existían dos formas de pensar, el verbal y el no verbal, representados respectivamente por el hemisferio izquierdo y el hemisferio derecho, el sistema educativo al inicio menosprecio la forma no verbal del intelecto.

De acuerdo a la información existente el cerebro humano está formado por dos hemisferios, unidos por el cuerpo calloso, que se hallan relacionadas con áreas muy diversas de actividades que funcionan de forma muy diferente, aunque complementarias.

Las últimas investigaciones en torno al funcionamiento del cerebro permitieron sondear zonas antes no exploradas, solo limitadas al ámbito de la especulación es así que se sabe que funcionan de manera diferente lo que da lugar a nuevos conceptos acerca de procesos intelectuales, ambos perciben una misma actividad de forma diferente, ambos utilizan modos de cognición de alto nivel.

Por lo tanto se puede plantear que es necesario establecer estrategias o herramientas que contribuyan al ejercicio de ambos hemisferios del cerebro.

Frenquelli en su artículo "Sobre Pavlov y su vigencia" especifica las funciones de ambos hemisferios. El izquierdo procesa la información analítica y secuencialmente, de forma lógica y lineal, abstrae, cuenta, mide el tiempo, planea, verbaliza, piensa en palabras y números, contiene capacidad para las matemáticas, para leer y escribir, emplea un estilo de pensamiento convergente, obtiene nueva información al usar datos ya disponibles, formando nuevos conocimientos.

El hemisferio derecho, sintetiza la información, se ven las cosas en el espacio, y como se combinan para formar el todo, gracias al hemisferio derecho entendemos las metáforas, soñamos, creamos nuevas combinaciones de ideas, es intuitivo en vez de lógico, piensa en imágenes, símbolos y sentimientos, tiene capacidad imaginativa y fantástica, espacial y perceptiva.

Se produce lo que denominamos intuición, momento en el que conectamos y nace la idea, este hemisferio emplea un estilo de pensamiento divergente, creando una cantidad y variedad de ideas nuevas más allá de lo convencional, es subjetivo y holístico, no verbal.

De acuerdo a Arias mencionado por Maranges se indica que "muchos matemáticos y científicos pueden desarrollar dotes artísticas y muchos artistas tales como pintores, escultores, músicos y deportistas pueden desarrollar una mayor lógica y análisis elevando el uso del hemisferio izquierdo".Asimismo manifiesta que el hemisferio menos desarrollado no reduce las funciones del otro, todo lo contrario se logra que el cerebro tenga un equilibrio entre ambos hemisferios. Afirma también que la creatividad en el ser humano es exclusiva de las personas que tiene el hemisferio derecho muy desarrollado. Esto les permite ser capaces de generar ideas creativas poco comunes que se combinan con el uso del pensamiento lógico y abstracto que aporta el hemisferio izquierdo de nuestro cerebro".

Betty Edwards (1979), publico el libro "Dibujar con el lado derecho del cerebro", en el campo del arte se asumió que el hemisferio derecho del cerebro, estaba relacionado con las capacidades artísticas, confirmando los estudios quirúrgicos de la década de 1960.Actualmente, las imágenes cerebrales tomadas mientras la persona realiza determinadas operaciones (matemáticas, poesía o música), son visibles las zonas específicas del cerebro activadas en cada caso, confirmando que en el hemisferio derecho radican muchas de las actividades propias del artista; sin embargo, con la comunicación constante entre ambos hemisferios se logra las creaciones más importantes, repercutiendo en nuestro éxito y sobrevivencia como especie.

En este punto es pertinente el comentario de Salomon H Snyder (2008) "las propuestas artísticas e intuitivas, 
son evidentes aún en los más abstractos logros intelectuales, como las teorías de Einstein". Por lo tanto, aunque razonemos con el lado izquierdo y soñemos con el derecho, nuestro éxito como especie radica en la continua comunicación y coordinación entre ambos hemisferios cerebrales.

Construcción del aprendizaje. De acuerdo a Flores, (2005), “Construcción del aprendizaje, es un proceso de atribución de significados, la construcción de una representación mental de un objeto o contenido". Las Bases del Aprendizaje, hace referencia al proceso por el cual adquirimos una determinada información y la almacenamos, para poder utilizarla cuando nos parece necesaria. Por ello, los cuatro procesos esenciales son: la atención, la memoria, la motivación y la comunicación:

El proceso de aprendizaje permite al sujeto su adaptación al entorno cultural, este proceso requiere de cambios en el sistema nervioso, de ahí la necesidad de la plasticidad del cerebro para poder tener capacidad de aprendizaje y de adaptarse a nuevas situaciones.

Para la docencia tiene importancia los diversos modos de representación de la realidad que tiene el cerebro, los pensamientos, emociones, imaginación y predisposiciones operan simultáneamente; estos interactúan con otros modos de adquisición y transformación de la información y con el aumento del conocimiento general, tanto social como cultural, de acuerdo a esto se hace necesario el uso de estrategias, de didácticas que les permita a los estudiantes orquestar experiencias de aprendizaje donde todos los aspectos de la operación del cerebro se consideren.

Grabado. La técnica de Grabado tiene su origen en China, a raíz de la invención del papel hacia el año 105, siendo la primera técnica la denominada xilografía como modalidad de bajo relieve, cuya matriz es la madera utilizada como método tipográfico.Teniendo como representante a Utamaro, Picasso, Mucha.

El grabado prospero en Europa en el siglo XIV y XV con la llegada de los procesos de elaboración del papel a este continente, es así que surge la calcografia cuya matriz es el metal, como técnica de bajo relieve, teniendo como representantes a Durero, Dore, Goya y posteriormente, la litografia cuya matriz es una piedra caliza como técnica planográfica teniendo como representantes a Toulosse
Lautre, Kathe Kollwich, Escher.

Como una técnica contemporánea aparece la Serigrafia, si bien históricamente apareció en Japón aplicando color y plantillas como técnica permeográfica, fue utilizada en el siglo XX como medio de expresión plástica. El término "serigrafia" escribir en seda es aportado por el artista plástico AnthonyVelonis. Las primeras impresiones con el método se realizaron en Estados Unidos, siendo utilizada por artistas plásticos como Andy Warhol.

Es así que el Grabado se ha venido desarrollando,incorporando nuevos medios que permiten nuevas formas de expresión artística, logrando calidades expresivas inimitables por otros medios artísticos, concordando con lo que afirma el artista Plástico y docente Peter Jones.

La experiencia de conocer y practicar las diversas modalidades del Grabado con sus procesos sistematizados nos proporciona resultados que en muchos casos enriquecen la propuesta inicial.

De acuerdo a Sánchez (2015), el concepto de Grabado ha variado desde sus comienzos hasta nuestros días. El grabado contemporáneo reivindica su esencia como proceso abierto, "en el que cada uno de sus pasos y estados es susceptible de variación, de integración con otros medios o de ser detenido y apreciado en cuanto objeto o momento estético".

Esto tiene relación con su carácter experimental y de obra abierta, en el que lo imprevisible es una de sus características, al no estar sujeto a resultados preestablecidos, sino más bien al descubrimiento las posibilidades que el propio proceso va ofreciendo en cada momento.

El grabado por la variedad de técnicas, así como las características de sus procesos hacen que se diferencie de la pintura y de la escultura en su proceso creativo.

En el grabado de acuerdo a la técnica se deberá considerar que los trazos que estamos realizando no siempre generaran una línea oscura sino todo lo contrario esta será blanca, se deberá trabajar áreas de la matriz para conservar el color que este impreso, se trabajara al revés por las características del proceso de impresión de técnicas como la xilografia, calcografia y litografia.

Se debe considerar aportes estéticos que se van originando en el proceso, siendo estos visibles a través de las copias denominadas de estado por lo cual se puede decir que al ejecutarla realizamos tanto procesos cognitivos racionales como los creativos emotivos, es decir se ejercita ambos hemisferios del cerebro. El grabado por sus características 
técnicas y plásticas tiene un carácter investigador y experimental esto como soporte prioritario que le ofrece una gran variedad de recursos.

Conclusiones. Podemos concluir indicando que ha existido una evolución respecto a cómo se construye un conocimiento, iniciando con los aportes de Piaget posteriormente Gardner con las inteligencias múltiples y la neurociencia asignando una capacidad para cada hemisferio donde se encuentran relacionadas los 8 tipos de inteligencias a las que alude Gardner.

Se deben desarrollar ambos hemisferios del cerebro importantes para la construcción del conocimiento, lo cual conduce a pensamientos más complejos originando mayores logros intelectuales.

El grabado por las características de sus diversas técnicas y procesos propicia la interrelación de los recursos creativos para analizar, reflexionar y resolver problemas. Asimismo, obliga a utilizar ambos hemisferios del cerebro logrando así una obra más innovadora acorde con las demandas actuales.

Efland, A., Freedman, K. y Stuhr, P. (2003). La Educación en el arte posmoderno. Barcelona. Editorial Paidós.

Effand,A. (2004).Arte y cognición:la integración de las artes visuales en el curriculum. Barcelona, España:Editorial Octaedro-Eub.

Gardner, H. (1987).Arte, mente y cerebro: una aproximación cognitiva a la creatividad. Buenos Aires Argentina: Editorial Paidos

Gardner, H. (1994). Estructuras de la mente:la teoría de las inteligencias múltiples. México: Fondo de cultura Económica.

Howard, P. (2010). Investigación neuroeducativa. Madrid. Editorial la Muralla.

Sánchez,A. (2015). Lenguaje y expresión en el grabado por aditivos y el gofrado. Una mirada personal sobre su especificidad artística. Universidad Miguel Hernández de Elche.

Frenquelli, R. (2010). Neuroanatomía y neurofisiología. Universidad Nacional de la Plata. Facultad de Humanidades y Ciencias de la Educación. http://www.memoria.fahce.unlp.edu.ar/programas/ pp.6534/pp.6534.pdf

Hernández-Chavarría, F. (2014). Creatividad: ¿derecho o izquierdo? ¡No, el juego de ambos! El Artista. Universidad Distrital Francisco José de Caldas Pamplona, Colombia. http://www.redalyc.org/
El artista, así como el diseñador gráfico no deben estar ajenos a lo que sucede en su entorno sean situaciones de índole personal social o políticas lo cual contribuirá a que reflexione, asuma compromisos y responsabilidades como profesional generador de obras y diseños con responsabilidad social lo cual contribuirá a un mejor futuro de nuestro planeta.

pdf/874/87432695021.pdf

Jensen, C. (2015).El Grabado como posivilidad de técnica artística y ecológica.Tesis de Licenciatura). Universidad Alberto Hurtado. Chile http://repositorio.uahurtado.cl/bitstream/handle/11242/24121/ PEPJensenH.pdf? sequence $=1$ \& is Allowed $=\mathrm{y}$

López, C. (2018)."Programa de estimulación de los hemisferios cerebrales en la construcción del aprendizaje en los niños de 5 años de educación inicial del distrito de Yúngar, Carhuaz". Universidad Nacional Mayor de San Marcos Universidad del Perú. Recuperado de "http://cybertesis.unmsm.edu.pe/bitstream/handle/cybertesis $/ 8424 /$ Lopez_gc.pdf?sequence $=1$ \&isAllowed $=y$

Maranges, G. (2013). Estimulación del hemisferio cerebral derecho y su relación con los aprendizajes educativos. Universidad Abierta Interamericana.Buenos Aires Argentina.http://imgbiblio.vaneduc. edu.ar/fulltext/files/TC112725.pdf

Martínez-Morga,M.,Martínez,S.Desarrollo y plasticidad del cerebro Revista de neurología. Recuperado de https://www.neurologia. com/articulo/2016019

Sanjurjo, B. (2001). La serigrafia como medio de expresión artística: (posibilidades técnicas). Universidad Complutense de Madrid. Recuperado de https://eprints.ucm.es/1720/1/T18972.pdf 